\title{
ROMANIA'S TOURISM POTENTIAL IN TRANSYLVANIA
}

\author{
Csoka Gabriela-Elena
}

\begin{abstract}
Tourism becomes a key element of the economy of any country or region that enjoys the existence of tourist resources that can be used. It is a well-known fact and, at the same time, very sad that in Romania, the tourism is under-exploited, although the tourism potential is extremely generous. Therefore, we set out to carry out a consistent study on the consumer behavior in hospitality and tourism demand and offers in Transylvania. Transylvania is one of the oldest and most beautiful historical and folkloric regions of our country. It is located in the center of the country and is the largest region in Romania, including ten counties. In addition to its rich history, Transylvania can boast impressive natural landscapes, but also with many spectacular sights, some of them unique in the country.
\end{abstract}

Keywords: tourism, potential, DMO, Destination Management Organizations, Transylvania.

JEL: $Z 32$ 


\section{Evolution of tourism demand within the development region of Bihor County}

Bihor County is a spa destination, this type of tourism practicing in local and national resorts located in the rural area. Urban tourism is a business one, especially because this county is located near the border. From the point of view of the tourist demand registered at the level of Transylvania we can characterize this destination as a whole, a cultural one, this type of tourism knowing in the specific case of the region an interesting combination of urban and rural tourism with cultural valences.

Cultural tourism is practiced especially in urban destinations with significant weightings at the level of all the tourist activity of the region also have the mountain and spa resorts of local and national interest. Rural tourism and tourist villages have, in their turn, made significant contributions to the tourism activity of the region. The only destinations that are absolutely insignificant in impact are those in the category "other mountain resorts".

Following the study of the strategic options of the tourist destinations, a number of aspects regarding the demand management for the tourist products of Transylvania and Romania can be retained. Thus, a first recommendation would be to initially opt for the practice of undifferentiated marketing, considering that the market must focus on the common elements of tourists and not those that differentiate them.

Given that the Romanian tourism does not benefit from unlimited financial resources, but rather faces budgetary constraints, it is considered that the elaboration of a unique offer can lead to attracting as many tourists as possible. At the same time, it is recommended to redo (in the sense of repetition) the market studies carried out on the target markets and the opportunity to identify some market segments for which communication strategies focused on them will be developed later.

From the perspective of strategies to stimulate demand by price, the DMOs have at their disposal various mechanisms, of which the cost-based methods, which address aspects such as: application of marginal quotas, analysis, covering aspects such as: applying marginal quotas, analyzing the profitability threshold or estimating the desired profit.

Regarding the level of the prices applied, it is appreciated that the moderate prices strategy represents the handiest solution for the destinations of Transylvania, which generally have a satisfactory performance in terms of quality, most likely attractive for tourists with average incomes.

As shown earlier, some microeconomic level price demand strategies are perfectly adaptable and applicable at the macroeconomic level (of tourist destination).

Some examples have been retained in this regard: the national programs to stimulate tourism - spa, rural, mountain or coastal etc., they are excellent variants to encourage tourist activity especially during the off-season, by lowering prices. 
The adoption of government policies in the sense of reducing VAT and for food services, respectively - in an ideal case - and for transport and/or leisure, provided for tourist purposes is another intervention through which the development of tourism can be supported.

The influence of the quantity demanded by the price can also be achieved at the level of Transylvania and by: discouraging the tourist consumption during the seasonal periods and stimulating it in the off-season, by practicing differentiated rates for the leisure services according to the moment of consumption or according to the categories of tourists received, and so on.

DMOs can intervene indirectly in setting prices using levers, such as increasing or reducing local/resort taxes or exempting from paying taxes, etc. It has been shown that the role of the DMOs is to ensure the coordination and synchronization of the price objectives of the destination with the individual ones of the local actors. Thus, in the specific case of Transylvania, consideration should be given to the orientation towards maximizing the use of the tourist reception capacity (the moderate prices creating an economic context perceived favorably by the tourists of the current year, and it is expected to determine more arrivals in the coming year) and on cost recovery for those destinations that are experiencing periods of non-utilization of the receiving capacity, which nevertheless entail operating costs.

Finally, the strategy of practicing cost-based pricing is one of the handiest means available to tourism providers for their coverage. From the perspective of setting the prices at the destination level, the DMOs have the role to coordinate the efforts of all the actors that cooperate at local and regional level for the development of tourist packages and can be involved in establishing the flat price directly or indirectly, by stimulating the granting of reductions in certain periods or certain categories of tourists / for certain destinations, or, on the contrary, by encouraging the increase of fares when appropriate.

\section{The stimulation of the tourist demand}

The stimulation of the tourist demand outside the season is another strategic lever that the DMOs from the tourist destinations can successfully use. This strategy, combined with cultural tourism and its promotion and stimulation, is probably one of the most useful means for improving the tourist activity in Transylvania, constituting an excellent means for making the best use of the tourist potential of the destination.

Stimulating the tourist demand outside the season can be achieved by developing tourist offers that are complementary to the forms of tourism practiced in the season 
(summer/winter mountain tourism, spa tourism, urban/rural/circuit cultural tourism, event tourism, etc.).

At the same time, the tourist demand can also be stimulated in the off-season by practicing lower rates (reducing the fiscal duties of the bidders during the off-season periods or in the seasons with unfavorable weather). Some of the initiatives may even belong to the bidders, who may, for example, offer additional services at certain times for free, which otherwise would be provided for a fee.

The DMOs (Destination Management Organizations) set up throughout Transylvania, respectively the three DMOs set up at the level of each development region, should be responsible for developing and implementing centralized reservation systems at the level of tourist destination.

From the perspective of the brand developed and being promoted, Romanian tourism is characterized by aspects such as: differences in perception between foreigners who have visited Romania and those who have not visited it (the first ones having opinions that are strongly favorable to the country, which is why it is considered benefits from intensified communication); Romanians are not aware of the tourism potential of indigenous destinations (experts' recommendations being to focus on symbolic destinations: the intact nature of the Carpathians and the Danube Delta, the cultural heritage, the painted monasteries, the areas with well-preserved traditions, etc.); among foreigners, the degree of notoriety of the Romanian tourist objectives is closely related to the actual visit of the country (those who have not visited it, are much less informed); In the case of foreigners who have not been to Romania, the history and / or culture and landscapes represent the uniqueness aspects of the destination, whereas for foreign tourists who have visited Romania, nature is identified as the main element of uniqueness (Carpathians, Danube Delta and the rural landscapes); those foreigners who have visited Romania would recommend it to a significant percentage also to other tourists; the attributes most associated with Romania are: authentic, rural, hospitality and green. In fact, they are also valid for Transylvania!

The problem of the tourist offer must be approached from the perspective of the three major categories of elements that constitute it: tourist attractions, tourist services, respectively the tourism and support infrastructure. Regarding the tourism offer, it is very important to remember the recommendation made by Goeldner and Ritchie (2006: 334), namely: "If you cannot maintain (a tourist objective/tourist attraction/tourist reception structure), better do not / build it!". 


\section{General considerations about the attractions and tourist resources of Romania}

The analyzes of the specialists revealed at the same time a sad reality, namely, that some of the most valuable objectives, attractions and tourist resources of Romania are found precisely in areas that are underdeveloped or even undeveloped from the point of view of infrastructure, which is why tourism was identified as the resource capable of ensuring their revitalization by exploiting their natural and cultural potential (according to analysts, Romania includes: areas with complex and high value tourism potential, which occupy about $24 \%$ of the entire country area and areas with high tourism potential, which occupy about $34 \%$ of the territory; they also add a lot of natural and anthropic tourist attractions, rich in opportunities for tourism development, but which have a lower density) (Dávid et al., 2013, Bujdosó et al., 2015).

Finally, Romania also concentrates over one third of the mineral and thermal waters of Europe, being one of the countries that set the base of the spa tourism since Antiquity, but in the absence of a specific infrastructure and appropriate support these very valuable resources are exploited well below the level to their real potential, the approximately 160 spa resorts - very few of European size and many only of local interest - offer numerous treatment possibilities for various medical conditions (rheumatic, gastroenterological, gynecological, nervous, etc.), as well as many recreational options and entertainment.

The analysis of the distribution of natural and anthropic tourism resources, respectively of the specific and support infrastructure at the level of the development regions of Romania and in the case of Transylvania led us to the following conclusions: in both cases, the percentage of localities with (many and many) tourist resources and with infrastructure problems it is overwhelming (79.2\% in Romania and $80.2 \%$ in Transylvania.

Regarding the natural and cultural resources included in the sphere of protected national heritage, a number of issues must be kept in mind: Transylvania concentrates about $49 \%$ of the total national and anthropic natural resources, as follows: $54 \%$ of the protected natural areas of national interest and of the natural monuments in Romania; $44.3 \%$ of all monuments and architectural assemblies and $33.1 \%$ of monuments and valuable archaeological sites.

These resources are found in localities with a high concentration of anthropic heritage with cultural value of national interest (47.9\%) and in localities with a high and very high concentration of tourist resources (53.9\%). The resources are distributed at the level of Transylvania as follows: in $43.4 \%$ of municipalities, $53.3 \%$ of cities and $47.7 \%$ of communes. One of the most valuable tourist resources is represented, both in the case of Romania, and especially in the case of Transylvania, are 
the cultural heritages which consisting of: immovable heritage - historical monuments; movable heritage - museums and archives; intangible heritage - aspects and landscapes cultural - public spaces.

Simon Anholt shows that the competitive advantage of any country/region is conferred by its culture, which can be assimilated to the rich and harmonious accompaniment of a simple song. Moreover, in his opinion, the culture offers a dignified country/region, an essential quality for any destination brand (either country or region). At the same time, culture is closely linked to tourism, cultural tourism is probably the tourism sector that enjoys the highest yield, the fastest growth and that mediates the creation of a connection between the interests of the people regarding a place itself and their interests related to the life of the place. In addition, Anholt also shows that destinations with a rich and varied cultural life manage to attract tourists from the upper classes, rich and civilized, a category of tourists, basically, from any destination.

Of course, given the natural and cultural supply of the Romanian and especially the Transylvanian destinations, we can conclude that two forms are dominant in the region's tourism: nature tourism and cultural tourism.

Unfortunately, this extremely valuable potential is not yet properly exploited and, moreover, it is prone to the danger of destruction by negligence, incompetence and lack of interest, the Romanian legislation being far too permissive when the question of withdrawing the status of historical monument or of element of cultural heritage of an objective (natural area, public space or building, etc.).

As a resume, we conclude the fact that Romania is a destination that enjoys a harmonious and diverse landscape, doubled by traditions and a rich culture, being perhaps one of the most beautiful and resource-rich places in the European space. Transylvania, as it turned out, is one of the favorite cultural destinations of foreigners arriving in Romania, being renowned for its multiethnic heritage, which makes it a familiar destination, easy to perceive and understand for European tourists, constituting a true sample of European cultural heritage (Coroş, 2014: 74-79).

The analysis of the evolution of the occupancy degree indicates a significant, even dramatic, decrease of this indicator in the case of the main accommodation structures, except for the urban and rural tourist pensions, respectively of the farms and of the agro-touristic pensions, where the values have remained constant at a modest level. Both Romania as a whole and Transylvania, in particular, enjoy very rich and varied natural resources, which constitutes, among others, an excellent potential for the development of mountain tourism.

As regards the analysis of Romania's tourism potential, it allowed us to formulate the following conclusions: despite the existence of an exceptional tourism potential, in Romania its exploitation and exploitation is improperly performed (the average rates calculated for internal and external factors are modest); although the forces of 
the Romanian tourism outweigh its weaknesses, the tourism sector, enjoying an external environment favorable to its development, must be strengthened in order to transform it into a real engine of the national economy.

\section{Conclusions}

It is recommended to create and implement a system at the level of Transylvania rather than making several systems for each type of tourism that can be practiced in the region (spa, mountain, cultural, rural, religious, including adventure, etc.), because, as shown, both the tourist demand and the tourist offer of Transylvania gravitate around the cultural tourism, which justifies the desire to promote Transylvania as a cultural destination.

As it results from the content of the paper, the specialized literature indicates a series of management strategies developed for the management of visitors of tourist destinations, dedicated in particular to the management of destinations in the category of protected sites and natural reserves.

The study of the literature devoted to the field of tourist destination management reminds us of the existence of an eternal dispute regarding the meaning towards which the destination management must lean, namely, towards the demand or the supply.

We appreciate that both aspects are essential for the development of Transylvania as a tourist destination and that more important than clarifying the mentioned dispute is to clarify the role of the DMOs, insisting on their functions.

The complexity of local and / or regional DMO interventions derives from the fact that they must coordinate all the actors involved and ensure the development of tourist destinations. In order to achieve their goal, they have (more precisely, it must have!) both political and legislative authority, as well as financial resources and highly qualified personnel.

Some of the most significant contributions of the DMOs are: maximizing the long-term destination strategy; to represent the regional interests and the tourism industry and of local and / or regional hospitality at national level; to maximize the profitability of local companies; maximize the effects of multiplication; to develop and promote a homogeneous and coherent image of the destination; to monitor how the destination is perceived internally and internationally (especially in the target and opportunity markets; as well as to optimize the tourism impact in the sense of sustainable development.

In the specific case of Transylvania it was concluded that it would be appropriate to set up at least four DMOs (of which three in each development region, and one organization in the whole of Transylvania) that will have to: elaborate the marketing 
strategies of the regional destinations and of the destination as a whole, focusing on both internal and external promotion, contributing to the development of local resources, specific infrastructure and support, opportunities for capitalizing on tourism and promoting socio-cultural and recreational initiatives.

The demand for the products of a tourist destination is determined by its attractiveness, which, in its turn, has its roots in the image of the destination and its perception, elements determined by the tourist performance and the actual tourist experiences, the reasoning of the tourist and the existing tourist information or offered at the destination level with a view to it.

\section{References}

[1.] Anholt S. (2003): Brand New Justice: The Upside of Global Branding. Oxford, UK, Butterworth-Heinemann, $180 \mathrm{p}$.

[2.] Coroş M. M. (2014): Managementul cererii și ofertei turistice. [PhD Thesis]. Cluj-Napoca, Univesitatea Babeş-Bolyai, Facultatea de Stiinte Economice și Gestiunea Afacerilor, Departamentul de Management.

[3.] Pop C. - Coroş M. M. (2011): Romanian Accommodation Establishments - An Investigation Regarding the Reasons for Their Development. Journal Studia Universitatis Babeş-Bolyai Negotia, Vol. 56. No.1. 5-27. p.

[4.] Todoran A. (2005): Cover Story - România ca brand. Business Magazin, No. $22(9 / 2005)$.

[5.] Qu H. - Kim L. H. - Im, H. H. (2011): A Model of Destination Branding: Integrating the Concepts of the Branding and Destination Image. Tourism Management, Vol. 32. No. 3. 465-476. p.

DOI: $10.1016 /$ j.tourman.2010.03.014

[6.] Bujdosó, Z. - Dávid, L. - Varga, D. - Pénzes, J. - Gyurkó, Á. - Zhakupov A. (2015): Tourism Development And Cross-Border Cooperation.The Hungarian-Romanian Border Region Geojournal of Tourism And Geosites, Vol. 16. No. 2. 153-163. p. Paper: 16103-178

[7.] Dávid, L. ; Bujdosó, Z. - Tóth, G. (2008): Tourism planning in the HajdúBihar - Bihor Euroregion In: Süli-Zakar, I. (Ed.) Neighbours and partners : on the two sides of the border. Debrecen, Magyarország, Kossuth Egyetemi Kiadó, 323-332. p.

[I1] ${ }^{* * *}$ Lori, Travel.PRWave.ro, Best Countries for Adventure Travel - Romania is One of Them!, in Travel - Moments in Time. Places We've Been, Things We've Seen, http://travel.prwave.ro/best-countries-for-adventure-travelromania-is-one-of-them, accessed on 19.02.2020. 
[I2] ${ }^{* * *}$ Romania, The fun is in the discovery, http://www.romaniandiscovery.com, accessed on 19.01.2020.

[I3] ${ }^{* * * * * *}$ Transylvania Travel, http://www.transilvaniatravel.com, accessed on 19.01.2020.

[I4] ${ }^{* * *}$ UNESCO, World Heritage Centre, http://whc.unesco.org/en/about/, accessed on 19.01.2020.

$[15]^{* * *}$ Un nou brand pentru promovarea externă a turismului, in România liberă, 7 mai 2005 ediția online: www.romanialibera.ro, accessed on 19.01.2020. $[\mathrm{I} 6]^{* * *}$

https://www.researchgate.net/publication/271443346_Managementul_cer erii_si_ofertei_turistice, accessed on 18.01.2020.

\section{Author:}

Csoka Gabriela Elena PhD

University assistant

Partium Christian University

University of Oradea 